\title{
A rua tem um ímã, acho que é a liberdade: potência, sofrimento e estratégias de vida entre moradores de rua na cidade de Santos, no litoral do Estado de São Paulo
}

The street has a magnet, I think it is freedom: power, suffering, and life strategies among homeless persons in the city of Santos, São Paulo, Brazil

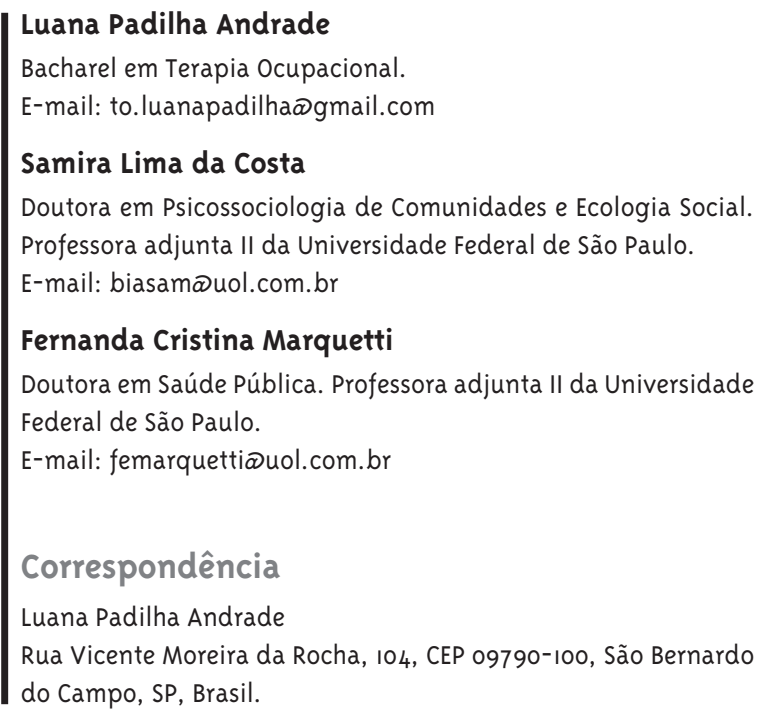

\section{Correspondência}

Luana Padilha Andrade

Rua Vicente Moreira da Rocha, 104, CEP 09790-100, São Bernardo

do Campo, SP, Brasil.

\section{Resumo}

O texto traz discussões acerca das estratégias de vida entre moradores de rua na cidade de Santos (SP). O levantamento dos dados ocorreu em 2009 e 2010, com acompanhamento de trajetória no território e coleta de narrativas de memórias de vida de todos aqueles que se identificaram como moradores de rua, eram maiores de 18 anos, e aceitaram participar da pesquisa. Os dados evidenciam inúmeras estratégias cotidianas de produção de vida e de projetos futuros, tanto nas ruas como fora delas. Identifica-se, também, a necessidade de aprofundar o debate acerca das políticas públicas voltadas a essa população que, até o momento e segundo a leitura dos narradores, concentram-se em propor modelos de intervenção restritos ao objetivo de retirada das pessoas ruas, o que não promove iniciativas pessoais e coletivas de transformação. Essas políticas públicas mostram-se impositivas, pois são pautadas pelo disciplinamento do comportamento social.

Palavras-chave: Sem-teto; Política Social; Terapia Ocupacional; Memória; Resiliência. 


\section{Abstract}

The text presents discussions on life strategies among homeless persons in the city of Santos, São Paulo, Brazil. The survey of data took place in 2009 and 2010, by tracking the pathway in the territory and gathering narratives of life memories of all those who claimed to be homeless persons, were over 18 years of age, and agreed to participate in the research. Data reveal numerous everyday strategies of life production and future projects, both on the streets and out of them. We also identify the need to deepen debate on public policies aimed at this population that, so far and according to respondents' reading, are focused on proposing intervention models restricted to the purpose of removing people from the streets, something which does not promote personal and collective transformation initiatives. These public policies show up as authoritative, since they are ruled by disciplining social behavior. Keywords: Homeless Persons; Social Policy; Occupational Therapy; Memory; Resilience.

\section{Apresentação}

O presente artigo foi baseado na experiência de campo de pesquisa realizada em Santos, cidade do litoral paulista, durante os anos de 2009 e 2010. Nesta foram investigadas pessoas em situação de rua tendo como objeto de análise suas memórias, afetos e planos de futuro. Apresentam-se aqui as reflexões produzidas neste contexto.

\section{A população em situação de rua na cidade}

A situação de rua ocorre no Brasil desde que o País era colônia. Período no qual as fazendas iniciaram a libertação dos escravos, mesmo antes da abolição (1888); muitos dos ex-escravos engrossaram consideravelmente a população em situação de abandono e de rua.

Esse contingente aumentou ainda mais com a chegada dos imigrantes camponeses, vindos da Europa, entre o final do século XIX e o início do século XX. Algumas cidades brasileiras criaram hospedarias e cortiços, acumulando grupos populacionais que, desde muito cedo, já ajudavam a desenhar a periferia urbana - ainda que central - no Brasil.

Nesse período, era comum a classificação desses novos moradores do perímetro urbano como "vagabundos", diferenciando-os dos demais não pela questão da moradia, mas pela inserção ou não no mercado de trabalho. No século XIX, a vagabundagem passou a ser crime, e a lei servia para classificar os moradores de rua (Justo, 2008).

Desde então, e com poucas mudanças, essa população sobrante da rede de produção e consumo tem lutado em busca de renda e moradia, sendo apoiada por políticas públicas e projetos filantrópicos. Os grupos se revezam e fazem rodízio entre hospedarias, cortiços e rua.

No município de Santos, o censo realizado em 2009 mostra que a população de rua tem crescido consideravelmente: em três anos, o aumento contabilizado foi de cerca de $60 \%$. De acordo com esse censo, os principais motivos que levaram as pessoas às ruas são: 30,1\% desemprego e perda de moradia. Outros $32,4 \%$ problemas familiares, alcoolismo e drogas ${ }^{1}$.

1 SEAS - SECRETARIA MUNICIPAL DE ASSISTÊNCIA SOCIAL DE SANTOS. Censo de população em situação de rua. Santos, 20o9. Documento Institucional. 


\section{A rua: espaço de ser e estar}

No Dicionário Larousse da Língua Portuguesa, Rua significa:

[...] 3 Os moradores de rua. 4 A plebe. Interjeição exprime despedida violenta e grosseira. R. da amargura: tortura, sofrimento. Arrastar pela rua da amargura: atacar a reputação, o crédito; descobrir os defeitos; dizer mal. Deixar (de herança) as ruas francas para passear: nada deixar. Encher a rua de pernas: vagabundar. Pôr na rua: a) dar liberdade, soltar; b) despedir; c) intimar alguém a sair da casa onde está ou mora. d) aparecer aos olhos de todos (Larousse Cultural, 1999, p. 802).

Assim, "pôr na rua" é dar liberdade e, ao mesmo tempo, é também intimar alguém a sair da casa onde está ou mora; significa, ainda, despedir. Mas que liberdade é essa que, ao mesmo tempo em que o sujeito pode ser livre, também é condenado por essa liberdade, perdendo espaços e direitos que até então lhe eram assegurados? Seriam incompatíveis, a liberdade, a moradia e o trabalho? Na definição citada acima, "sair à rua" significa aparecer aos olhos de todos, sugerindo que a rua é espaço público, de visibilidade. Porém, quando se trata do morador em situação de rua, a visibilidade pode se confundir com invisibilidade.

Há aí uma forte contradição: pois, ao mesmo tempo em que os moradores em situação de rua são um evento essencialmente urbano, eles causam, permanentemente, estranhamento e rejeição, como se não pertencessem àquele espaço.

O termo RUA também é definido por "moradores de rua”, sugerindo que o sujeito que reside nas ruas é, ele mesmo, a própria rua. A RUA é ainda associada ao espaço no qual a "exposição dos defeitos" é sinônimo de atacar a reputação. Além disso, "deixar as ruas francas para passear" significaria não deixar nada, portanto, ter a rua é não ter nada. 0 termo é também associado à ideia de vagabundear. Nas definições do dicionário, o termo é envolto por um arsenal de características pejorativas: plebe, tortura, falar mal, despejo. Porém, há ali uma perspectiva de qualidade positiva das ruas: a liberdade, como já dito acima (muito embora a mesma liberdade também ganhe caráter negativo, na forma de "vagabundagem”).

Por outra via, ao abordar a questão dos mora- dores de rua, o conceito de Rua nos leva à reflexão sobre a histórica questão entre os conceitos de público e privado. Richard Sennett denominou "vírus da intimidade" a tirania da intimidade que se manifesta em vários sintomas: promoção exclusiva de relações sociais fundadas na personalidade, uma "psicologização" da vida social, valorização excessiva das relações privadas em detrimento das relações público/sociais e outras (Sennett, 1988). Essa idolatria da intimidade e degradação da vida e espaços públicos a que o autor se refere está muito presente na sociedade contemporânea, em que observamos um recolhimento de todas as práticas sociais, afetivas, cotidianas, de consumo, em direção a espaços da vida privada.

Ao contrário de caracterizar a vida na rua pelas rupturas e dificuldades, Sennett (1988) afirma uma positividade transgressora do ato de viver nas ruas. 0 morador de rua transforma o espaço da cidade no qual habita, pois interfere nas práticas cotidianas de um lugar, redimensiona lugares, (re) significa equipamentos públicos, reinventa relações sociais, e principalmente, interfere nas concepções público-privado. Ao exibir sua vida "privada" no espaço público, ele traz à cena imagens invisíveis ao cenário urbano.

O tema da liberdade emerge nas narrativas dos entrevistados de forma recorrente. Considerando as contradições que parecem se relacionar ao tema e à centralidade que ele ganha nas narrativas dos sujeitos pesquisados, faz-se a seguir um breve estudo a seu respeito. 0 mesmo dicionário citado acima define que liberdade é, dentre outras coisas:

Estado de pessoa livre e isenta de restrição externa ou coação física ou moral; Poder de exercer livremente a sua vontade; Condição do ser que não vive em cativeiro; Dir Isenção de todas as restrições, exceto as prescritas pelos direitos legais de outrem; Independência, autonomia; Ousadia; Permissão (Larousse Cultural, 1999, p. 567).

Vemos na definição acima que liberdade pode ser compreendida como estado de pessoa livre e isenta de restrição externa ou coação física ou moral. A princípio, numa análise strictu senso, poderia se afirmar que essa liberdade não existe no plano concreto da vida. Entretanto, o mesmo termo prevê a isenção de restrições, mas abre exceções às pres- 
critas pelos direitos legais de outrem. Essa, por si só, não seria uma restrição moral ao próprio conceito? Quem é esse outrem, e quais seus direitos legais? Seriam outrem todos os outros moradores e transeuntes da cidade? Como definir quais os direitos legais do morador em situação de rua, posto que, por princípio, a própria situação de rua caracteriza a violação de um dos direitos sociais básicos: a moradia? Que isenção de restrições estaria garantida ao morador em situação de rua de fato? A liberdade, nas ruas, constitui-se como um acordo coletivo que se estabelece na convivência.

As regras de conveniência de um bairro determinam as possibilidades de vida num espaço público, seja para moradores, comerciantes, transeuntes, seja para moradores de rua. A vida cotidiana num bairro se organiza em dois registros: o comportamento e os benefícios simbólicos advindos dele. $\mathrm{E}$ entre estes dois sistemas há uma forma de regulação pela "conveniência” (Mayol, 1996).

O comportamento do sujeito no bairro se caracteriza por inúmeros aspectos: seu vestuário, códigos de cortesia, seus gestos sociais, seu ritmo, seus itinerários, os habitantes com os quais convive, os lugares frequentados etc. A partir destes comportamentos, o sujeito será inscrito num lugar simbólico dentro do bairro, que possui seus benefícios e/ou malefícios simbólicos. É quase imediato imaginar a ruptura das inúmeras regras de convivência efetivada pelos moradores de rua num bairro e suas consequências.

Se nas regras de convivência do bairro cada pessoa sustenta uma vida possível no lugar, o morador de rua é aquele que produz rupturas permanentes dos códigos implícitos na localidade. Assim, como há códigos de convivência estabelecidos nos bairros, também entre os moradores de rua há um código, com regras que podem mudar de um lugar para o outro: não poder dormir em lugar que já é de outro, não invadir o território de renda de outras pessoas, ter que compartilhar bebida, comida, cigarro e fogo, entre outros.

Tais códigos também variam, conforme o uso que cada grupo faz das ruas, o que nos leva a pensar também nas diferenças que existem entre ficar na rua, estar na rua e ser da rua. Ghirardi e colaboradores (2005) dizem que essa variação semântica parece traduzir um movimento de adaptação que vai do transitório ao permanente, num espaço público. Ficar na rua é ainda preservar e manter uma rede de relações de suporte. Estar na rua é estruturar progressivamente um novo cotidiano que tem como referencial o espaço público, com seus moradores e usuários. Ser da rua é tornar este espaço seu cotidiano real, tendo a rua como moradia e local de trabalho, ir se desvinculando gradativamente das suas redes sociais de suporte e aderindo aos códigos que imperam nas ruas.

As políticas públicas para esta população (Brasil, 2005, 2009) vêm adotando a expressão "em situação de rua", considerando também, dentro deste espectro, a precariedade de vínculos de moradia - como casas de passagem e abrigos. Sobre esta expressão, um dos participantes desta pesquisa comenta:

Não sei por que "que" vocês falam assim: "em situação de rua". Quem mora em um apartamento tá "em situação de apartamento?". Não! É morador de apartamento, né? Tem gente que tá na rua porque tá passando uma situação, aí tudo bem. Mas eu não estou em situação, porque moro na rua faz anos, $e$ eu sou morador de rua, mesmo. Não é uma situação, é minha casa, é minha vida, entende o que eu "tô" dizendo pra você?? (C.D.).

Entendendo que a expressão "em situação de rua" problematiza a questão da falta de moradias, implicando gestores e políticas públicas para que esta seja de fato uma situação transitória, neste artigo se mantém o uso dessa expressão. Entretanto, tomando a discussão de Ghirardi e colaboradores (2005) acerca do tema "ser da rua" apresentada acima e, principalmente, considerando a fala anterior, neste artigo, nos momentos nos quais se faz referência aos participantes da pesquisa, será utilizado o termo "morador de rua”, e não "pessoa em situação de rua".

\section{Terapia ocupacional: referencial teórico para a questão da situação de rua}

Estar nas ruas é estar mergulhado nas situações de um cotidiano público, não apenas quando se mora nela, mas também por frequentá-la. São essas situações, as adversidades e os encontros, que auxiliam no processo de construção de identidades individuais e coletivas. 
Lembrando Heller (1972), a formação dos indivíduos começa sempre nas esferas da vida cotidiana. A ação do terapeuta ocupacional social dá-se na problematização de um fazer (re)significado pelo sujeito ao olhar para si mesmo como sujeito histórico e político. A atividade cotidiana é indissociável da vida humana. Muitas das atividades cotidianas se repetem com uma frequência regular e se tornam rotina; outras surgem, saem e/ou se transformam ao longo da vida.

Adotamos os conceitos de comportamento maquinal e cadeias operatórias de Gourhan (1966) para compreender o cotidiano: "o comportamento maquinal é relativo às cadeias operatórias adquiridas pela experiência e pela educação" (p. 26), que são inscritas no comportamento gestual e na linguagem. Essas cadeias operatórias desenvolvem-se numa "zona de penumbra" constituída por gestos maquinais, incorporados no cotidiano do sujeito e não perceptíveis como gestos ou atos significativos. As cadeias operatórias são "práticas elementares" e básicas, no entanto, vitais ao indivíduo: "seus hábitos corporais, práticas de alimentação ou de higiene, comportamentos de relação com seus semelhantes", ou ainda, gestos profissionais, gestos do cotidiano, cujo recurso assegura o equilíbrio do sujeito no meio social e no seu próprio conforto psíquico. 0 sujeito emerge quando incorpora (ação corporificada) um conjunto de cadeias operatórias socialmente consensuais e que viabilizam o seu com-viver.

O conceito de cadeias operatórias é de especial interesse para a Terapia Ocupacional, na medida em que esta privilegia o cotidiano e seus gestos banais como um de seus objetos de estudo e atuação. Na Terapia Ocupacional, o cotidiano:

[...] é a área de atuação mais elementar e significativa, pois nele se conjugam as atividades que o homem desenvolve durante sua vida, construindo mundos plenos de sentidos. As atividades cotidianas, aparentemente comuns, rotineiras, elementares conformam os fundamentos dos modos de viver humano. Nossa vida é composta de gestos ínfimos e elementares que, embora pareçam insignificantes, viabilizam o nosso viver cotidiano. Diariamente construímos e refinamos os processos de interação do corpo no seu meio, a coordenação de ações e emoções com os outros, e transformamos no tem- po e espaço vividos esse gestual cotidiano que ao longo da nossa existência compõe a própria vida. (Marquetti, 2011, p. 219).

Nas ruas, as cenas cotidianas, que se passam à volta das pessoas, influenciam diretamente na estruturação desse cotidiano, ou seja, a vida de quem mora nas ruas e suas cenas cotidianas são regularmente redesenhadas por fatores externos. Como a pessoa lida com essas mudanças, como ela encara essa influência da vida pública em sua produção de vida, cotidiana e de privacidade, vai depender de como as relações se dão, de como ativa suas redes e de como produz suas memórias e planos. A vida cotidiana produz os modos de agir, pensar e sentir nos processos afetivos, cognitivos e comportamentais.

Quando a automatização de determinadas atividades não é sustentada pelo cotidiano a sua volta, essas atividades precisam ser adaptadas; com isso algumas vezes podem perder ou transformar seu sentido. É possível que a pessoa não se sinta - ou deixe de se sentir - pertencente a determinado grupo ou local no qual se encontra, e onde sua vida acontece. De acordo com Barros e colaboradores (2002), a Terapia ocupacional é um campo de conhecimento com foco social, educacional e em saúde, que "[...] reúne tecnologias orientadas para a emancipação e a autonomia de pessoas que, por razões ligadas a problemáticas específicas [...], apresentam, temporária ou definitivamente, dificuldades de inserção e participação na vida social” (p. 366).

Nessa perspectiva, a organização do cotidiano e suas transformações socialmente determinadas se constituem em foco de interesse da terapia ocupacional social que, apoiada nos referenciais sociológicos e antropológicos, possui como objeto de estudos a relação das pessoas com seus fazeres, juntamente com o sujeito em questão. Ela busca problematizar a situação vigente, a fim de identificar (re)significações para o fazer na vida cotidiana, favorecendo para que o sujeito seja, ele mesmo, o objeto transformador, o catalisador dessa mudança, possuindo por inteiro seu processo de transformação, tanto pela apropriação de situações rotineiras, na produção e potencialização de redes sociais e de suporte, quanto pelo processo de busca e garantia de direitos, na ativação de redes de assistência. De acordo com Costa (2012), a Terapia Ocupacional Social: 
...toma como base a complexidade das trocas sociais e os contextos sócio-históricos, investindo na elaboração participativa de projetos que promovam a garantia de direitos que ampliem a potência das atividades do cotidiano como formadoras e reguladoras das relações entre pessoas, ambientes e contextos (p. 44).

Desta forma, o terapeuta ocupacional social contribui para ampliar as bases teórico-conceituais que apoiam a reflexão e a construção de políticas públicas. 0 plano, aqui, não é o plano do terapeuta, ou o projeto dos gestores públicos ou mesmo das entidades. Não é o plano que a sociedade tem para o morador de rua, mas o plano que ele tem para o lugar da rua e da sociedade em sua vida. O trabalho é de estratégias de vida nas ruas, com as potências e as limitações que este amplo espaço impõe.

Considerando a relação da pessoa em situação de rua com a própria rua, o conceito de cotidiano torna-se fundamental, pois será nas suas sutilezas que vamos conhecer o sujeito. Utilizamos a concepção de Certeau sobre cotidiano:

O cotidiano é aquilo que nos é dado a cada dia, nos pressiona dia após dia, nos oprime, pois existe uma opressão do presente [...] O cotidiano é aquilo que nos prende intimamente, a partir do interior. É uma história a meio caminho de nós mesmos, quase em retirada, às vezes, velada (Certeau, 1996, p. 31).

Esta opressão natural do cotidiano mostra-se pungente aos moradores da rua, devido às próprias fragilidades impostas a quem vive nas ruas, bem como pelas inúmeras rupturas promovidas pela perda das redes sociais. E, como o cotidiano aprisiona intimamente, nos moradores de rua esta prisão se dá a partir da rua, seu espaço mais íntimo. Curiosa ambiguidade: a rua torna-se espaço íntimo e aprisiona o sujeito. Talvez, por isso eles tenham sentenciado: "A rua tem um imã!".

\section{Memória e cotidiano nas ruas}

A partir da caracterização da rua como espaço próprio, começa então uma nova fase da vida do sujeito, diferente (ainda que não totalmente) daquela em que vivia anteriormente e sobre a qual constrói novas memórias e planos de vida, que ganham novas formas e significados.
Segundo Halbwachs (2006) e Costa (2008), a memória humana não é uma reprodução das experiências passadas e sim uma construção que se faz a partir daquelas, por certo, mas em função da realidade presente e com o apoio de recursos proporcionados pela sociedade e pela cultura. Portanto, a construção, a manutenção e a atualização da memória social, mesmo em suas manifestações mais pessoais, dependem da interação e da comunicação sociais.

Assim, as memórias são construções de experiências passadas, a partir do momento presente. Essas experiências são vividas dentro dos diferentes contextos em que as pessoas estão inseridas: seu cotidiano, que indica a relação espaço-temporal na qual se dá essa vivência. É no cotidiano que se revelam as atividades exercidas sobre um território, onde se desenvolvem as diferentes práticas sociais e suas respectivas interações sociais através do tempo.

No cotidiano surge a identidade destes moradores de rua, que formam sua enunciação através da ação. E, assim, reconhecemos o sujeito forjado num território a partir de seus atos, sua identidade construída na rede das relações sociais, e permite-se a ele ocupar seu lugar simbólico. Neste mosaico de ações estabelecidas, através de fragmentos do cotidiano, forma-se um sujeito. É nesta história de ações sutis que descobrimos estes "sujeitos da rua" sendo construídos diariamente pelos seus gestos. “[...] Deve atentar-se para o comportamento, e com exatidão, pois é através do fluxo do comportamento - ou, mais precisamente, da ação social - que as formas de cultura encontram articulação" (Geertz, 1989, p. 27).

Grande parte da população passa um bom período do seu dia nas ruas, entre as ruas e seus domicílios. E é esta fronteira, que separa o espaço público e o privado, marcada pela separação objetiva de espaços, desenhada por muros, que contribui para a formação da identidade do sujeito. Para uma pessoa que mora nas ruas, essas vivências são muito mais acentuadas e complexas, pois é nas ruas que ela encontra sua identidade, é nelas que acontecem as cenas cotidianas de sua vida, é nelas que é produzida sua percepção de privacidade e de publicidade.

Nesta medida, podemos observar as populações que moram nas ruas como transgressores daquela 
forma hegemônica de viver das sociedades contemporâneas, descrita por Senett (1988) como "tirania da intimidade". Estes sujeitos, usando os espaços públicos para sua vida íntima, criam uma fissura nas fronteiras entre público e privado. Talvez a forma de viver desta parcela da população citadina recupere ou reinvente os usos do espaço público. Neste sentido, temos em Magni (2006) uma perspectiva que avalia a população das ruas como segmentos sociais nômades que divergem da norma sedentária que se tornou condição fundamental na construção e desenvolvimento das cidades, como forma de organização da vida coletiva de forma privada. Para a autora, a não fixação dos habitantes de rua promove uma mobilidade espacial e existencial, gestando novas formas de vida com características únicas.

As pessoas vão para as ruas por diversos fatores, mas todos apontam para uma fragilidade em sua rede social, com seus suportes e cobranças. A rua pode não oferecer suporte, mas diminui as cobranças e oferece maior liberdade, ainda que relativa.

Cabe, então, construir os percursos e a memória social deste coletivo. A memória social distingue-se marcadamente das demais por se caracterizar por construções sociais em constante transformação, ao mesmo tempo em que resiste e busca sustentar algo do passado no presente (Costa, 2008). Esta memória e seus processos, transitórios ou não, geram inúmeros afetos e afetações, que podem ter diferentes significados. Essas experiências refletem na maneira de agir e pensar desse sujeito. Seu modo de encarar a vida, o mundo, sua realidade particular e tudo que a compõe também se modificarão.

\section{Método}

O estudo caracterizou-se como pesquisa social, tendo contado com acompanhamento de trajetórias nas ruas e entrevistas abertas na forma de narrativas sobre memórias de vida de pessoas em situação de rua na cidade de Santos, durante o período de um ano e meio (entre 2009 e 2010); aqueles que concordaram em participar da pesquisa foram acompanhados em seu cotidiano e tiveram suas narrativas ouvidas².
O recurso metodológico para a coleta de dados foi o registro de narrativas livres de memória de vida, pois é uma técnica de pesquisa que permite o acesso aos sentidos atribuídos e a reconstrução de experiências dos indivíduos no que concerne à realidade da vida cotidiana e suas construções. A narrativa é uma técnica de recapitular a experiência passada através da combinação de sequência verbal de sentenças com a sequência de eventos que (infere-se) de fato ocorreram. "Através da narrativa, as pessoas lembram o que aconteceu, colocam a experiência em uma sequência, encontram possíveis explicações para isso, e jogam com a cadeia de acontecimentos que constroem a vida individual e social" (Lira e col., 2003, p. 61).

A narrativa insere-se no conceito das técnicas de pesquisa que fazem parte das metodologias de Pesquisa Social, que é toda pesquisa que busca respostas de um grupo social, centrando atenções na base qualitativa da informação.

O estudo, habitado pela narratividade, não procura, portanto, expulsar da casa dos autores os vivos e os mortos que a habitam, para fazer deles "objetos de análise". O estudo se articula em torno da relação que a sua estranheza mantém com uma familiaridade (Certeau, 1996, p. 32. Grifo nosso).

Esse tipo de pesquisa não pretende um distanciamento entre sujeito pesquisado e sujeito pesquisador, pois a narrativa produz afetações a ambos os sujeitos. Lembrando Costa e Carvalho (2011, p. 68), "enquanto narra, a memória se produz. Enquanto narra, o narrador lembra, afetando e sendo afetado no encontro com o seu ouvinte".

As narrativas foram analisadas através do agrupamento em categorias semânticas, seguido de reflexões à luz do referencial teórico da pesquisa.

\section{Discussão}

\section{Razões pelas quais foram para as ruas}

São diversas as razões que fazem as pessoas irem para as ruas, algumas vezes por opção; outras, por falta e opção. As pessoas que dizem ter escolhido

2 A pesquisa ocorreu dentro dos preceitos da Resolução no 196/96 do Conselho Nacional de Saúde do Brasil sobre pesquisa com seres humanos. 
voluntariamente as ruas, aparentemente têm maior facilidade de adaptação neste ambiente. Dizem estar em busca de algo - na maioria dos casos, buscam a liberdade - e, assim, entendem as ruas como um recurso necessário para alcançarem seus objetivos ao saírem de casa. Cinco dos entrevistados dizem ter optado por ir para as ruas em função da liberdade. A rua tem um Ímã [...], acho que é a liberdade (M.S.). Eles vieram para as ruas em busca dessa liberdade, desligando-se de seus vínculos familiares por escolha própria. Foi assim também com C.R., que aos sete anos de idade fugiu pela primeira vez de casa. Encontrado, tornou a fugir e completou a maioridade nas ruas: A vida em família não era pra mim (C.R.). Quando essa ruptura com a vida pregressa é algo programado, nem sempre o que se passa com a pessoa é de conhecimento dos familiares. Eles não sabem que eu moro nas ruas. Não quero preocupar meus familiares (S.P.). Suas falas se diferenciam das falas de quem não está nas ruas por opção. Há uma grande diferença de quem aparenta apenas ficar, de quem está e de quem é das ruas.

Quem vai para as ruas devido a circunstâncias adversas, apresenta movimentos de resistência aos modos de vida e à permanência nas ruas. Assim, as falas das pessoas que não optaram por estar ou ficar nas ruas seguem por caminhos contrários às falas anteriores: Eu não quero falar das ruas não... Isso aqui não é vida pra ninguém (D.L.).

\section{Ruas e casas}

Embora o Brasil já tenha gerações que nasceram nas ruas, este não foi o perfil das pessoas encontradas nesta pesquisa. Todos os entrevistados tiveram experiência de família, trabalho e vínculos afetivos antes da experiência de rua e dizem haver vantagens e desvantagens tanto nas ruas quanto em casa.

Muitos dos narradores, ao falarem da experiência doméstica, elencam aquilo de que mais sentem falta: o conforto, a "tela" (televisão), os móveis (como referência de "casa"), a privacidade, a família, a proteção que uma casa oferece. Ainda assim, muitos afirmam que não trocam as ruas e sua liberdade por uma casa novamente: Nas ruas tenho liberdade; em casa tenho que cumprir com as obrigações, dar satisfação e ter horários (D.C.L.). A liberdade para fazer o que quer, ir e vir aonde, quando, como e com quem quiser, são motivos que aparecem em suas falas.

Enfim, há nas ruas uma imensidão de coisas que tornam mais palpável a sensação de liberdade, mesmo que relativa: $\varepsilon u$ sei que aqui a gente às vezes tem que levantar, sair... Mas sou eu que escolho onde vou encostar, com quem, que hora... Eu penso: "hoje vou na praia". E vou. Ou então "eu vou acharcar (pedir esmola) aqueles ali”. $\varepsilon$ daí vou, entendeu? (C.D.).

A construção do cotidiano emerge como fator decisivo para a permanência nas ruas. O hábito, descrito através do fato de ter se "acostumado" com as ruas, aponta para uma dificuldade, em oposição, para se acostumar novamente com "a casa": Não tenho nada contra a casa, mas na rua tem liberdade, e também já tô acostumado (C.R.). Uma fala bastante comum é sobre a possibilidade de fazer uso de drogas nas ruas: Com a droga fico muito elétrico, a droga dá um barato... Não conseguiria mais morar em um apartamento com o efeito da droga! (S.J.).

Outros dizem que a casa é um espaço da rua, espaço opressor e violento: Nas ruas tem que dormir com um olho aberto e o outro fechado. Se vacilar vem um e te rouba. $E$ se eu perder meus documentos, aí acabou tudo (S.P.). J.P. em seu relato diz já estar acostumado a morar nas ruas, e que gosta da liberdade que ela proporciona, mas entende que esta situação dificultaria outras experiências, como ter filhos por exemplo.

Alguns falam do sofrimento nas ruas: Tenho medo daquela tal depressão. Procuro sempre estar alegre, sorrindo, brincando. Mas às vezes a gente fica triste. Bate a saudade de antigamente. Aí eu choro, choro muito. Chorar faz bem, né? (D.L.). Esta fala ilustra algo comum em suas falas: mesmo entre os que afirmam não desejarem retornar à vida doméstica, é comum o sentimento de tristeza relacionada à saudade da vida pregressa.

\section{Dinheiro e renda}

Um aspecto que têm em comum é a dificuldade para conseguir dinheiro nas ruas. Cinco são catadores de materiais recicláveis, e têm encontrado cada vez mais concorrência. Na década de go era possível manter o aluguel de uma residência, atualmente não sustenta de um quarto. Cato latinha, mas é difícil porque tem muita gente que cata. Quase não sobra (S.P.).

Outros quatro dizem fazer "bicos": olhar carros 
na rua ou fazer pequenos serviços no porto. Por ser uma cidade de praia, outro bico comum é ajudar nas barracas da praia, apesar de ser uma atividade sazonal, mais frequente nas temporadas de verão: $\varepsilon u$ monto barracas na praia, pra tirar um troco (F.D.). E embora essa seja uma prática comum entre os moradores em situação de rua em Santos, apenas um deles afirma ganhar dinheiro só com a mendicância: Fico aína rua, acharcando (pedindo esmolas) (C.R.).

Para alguns deles o objetivo de ter a própria renda não mudou após terem vindo para as ruas. É o caso de alguns que trabalham com materiais recicláveis ou fazem bicos: Faço meus bicos, não desisto. Ainda não consegui assinar a carteira, mas vou conseguir! Vou alugar uma casa e poder dar um retorno para a minha família, ajudar elas! (D.L.). Nesta fala, aparece um item pouco referido pelos entrevistados: o desejo de ser trabalhador formal. Embora a questão da renda seja central para a maioria dos entrevistados, a lógica do trabalho fixo e da estabilidade da renda foi mencionada apenas por D.L.

\section{Relações cotidianas}

As relações cotidianas relatadas pelos entrevistados dão-se em diversos ambientes, com diferentes pessoas e com variados graus de intensidade e frequência. Segundo Gaspar (2006), é também na rua, que nós formamos a rede de relações humanas e a nossa identidade.

Algumas relações mais frequentes, como os que trabalham, dormem e/ou andam juntos, com quem dividem experiências cotidianas: $\varepsilon u$ e meu amigo conversamos, eu conto minhas saudades, ele fala as dele, e assim vamos levando. [...] Sabe, mesmo com tudo que eu passo, sou feliz! Tenho saúde, pessoas que me tratam bem, amigos. Por isso que sou feliz (D.L.). Outras são fugazes: Quando a gente leva uma trombada de outra pessoa, saca? Esse tipo de relação ébem ruim, porque mesmo se a gente não teve culpa, pra eles a gente é sempre culpado, porque parece que... Tipo, parece que não era nem pra tá ali, que não era nem pra existir, tá ligado? (C.D.).

Em maior ou menor grau, as relações dão-se o tempo inteiro e são fundamentais para a construção do cotidiano na vida das pessoas e grupos sociais. Pádua e Magalhães (2003) discutem que, se tais relações podem ser emocionalmente satisfatórias pelos laços afetivos como a autenticidade e a confiabilidade, igualmente podem ser estressantes, pela possibilidade de dissolução e alienação pelo caráter solitário e pouco coletivo de suas tensões.

Portanto, as relações não são fixas. Cada fato novo nas relações e na vida muda a forma como encarar as pessoas e as situações. As formas como as relações e as redes existem produzem maior ou menor grau de suporte social. É a baixa qualidade de tais relações que produz os processos de vulnerabilidade social, caracterizada por fragilidade e fugacidade das relações, ausência de suporte permanente, caracterização do cotidiano por relações superficiais ou por processos de ruptura dos vínculos profundos. São as redes de suporte que oferecem o auxílio necessário para alcançar e manter o equilíbrio dinâmico entre integridade e vulnerabilidade. Lembrando Castel (1994), nos momentos em que as redes de suporte encontram-se também fragilizadas, esgarçadas, é necessário que se ative outra rede: a rede pública de assistência.

\section{Equipamentos da proteção social e de segurança pública}

Santos é uma cidade que conta com uma ampla gama de dispositivos de apoio à população em vulnerabilidade social. Esses dispositivos fazem parte tanto da (vasta) rede filantrópica de assistência quanto dos serviços municipais da Secretaria de Assistência Social (SEAS). Por estarem em situação de violação de direitos, as pessoas em situação de rua são caracterizadas como em situação de risco social, motivo pelo qual contam com o apoio dos serviços de média e alta complexidade da proteção social especial. Entre as unidades especializadas da Proteção Social Especial, três delas atendem especificamente à população em situação de rua, mas apenas uma foi mencionada pelos participantes desta pesquisa: a Seção de Acolhimento de Adultos, Idosos e Famílias em Situação de Rua (conhecida como "Casa Aberta”).

Há também na cidade Organizações Não Governamentais e casas religiosas que acolhem pessoas em situação de rua e oferecem cama, banho e/ou alimentação, que compõem a rede filantrópica de assistência, bastante vasta na cidade de Santos. Durante as narrativas apenas uma ONG foi citada: o Albergue Noturno. Tal oferta de serviços e 
acolhimento é compreendida pelos entrevistados como um atrativo da cidade: Quem mora na rua de outras cidades, se descobrisse Santos nunca mais ia embora. Em Santos tem tudo. Tem onde comer,onde tomar banho, onde cortar cabelo, onde arrumar roupa (M.S.).

Alguns nunca frequentaram nenhuma dessas instituições e outros passaram por um ou por ambos. Dos onze entrevistados, seis já passaram pela Casa Aberta. Destes, nenhum diz querer um dia voltar para lá: Frequentei a Casa Aberta por dois dias, pra nunca mais (J.P.); Não passo mais nem perto de lá. [...] Lá eles maltratam os moradores de rua. Tudo fede, é sujo (D.C.A.); e Eu tô na rua, mas eu tenho minha higiene (D.C.L.). Muitos se queixam da rotina rígida do serviço e do ambiente insalubre. Entre os que passaram pela "Casa Aberta", todos responderam que preferiam as ruas, pois nas ruas eles escolhem sua rotina: Na Casa Aberta todo mundo fica junto, não dá pra escolher se vou ficar perto ou não de uma pessoa fedida, bêbada, drogada... Tem tráfico, tem gente usando droga... Eu, hein! Sou mais ficar aqui fora! (F.D.).

As vantagens e desvantagens da "Casa Aberta" se difundem facilmente entre a população de rua. Um conta para o outro. Este é um dos principais motivos pelo qual quatro dos dez entrevistados nunca foi à "Casa Aberta", mas conhecem bem o que acontece por lá, e têm resistência mesmo sem nunca ter frequentado, como é o caso de M.S. e D. L: Não conheço não, mas Deus me livre ir para um lugar desses (M.S.). A partir de relatos de terceiros, eles vão tecendo uma imagem dos lugares, dos equipamentos. Produzem para si uma "memória da memória". Deixam claro em suas falas que melhor do que o "teto" do equipamento é a sua organização nas ruas, sua segurança, sua liberdade de escolher aonde ir e com quem andar: Lá é sujo, o povo usa droga, bebe, dá facada. Deus me livre, prefiro ficar aqui do lado de fora (D.L.).

Três entrevistados já estiveram no Albergue Noturno e têm melhores avaliações: $\tilde{\varepsilon}$ bom, é limpinho, tem uma comida boa... (S.P.). A semelhança entre os equipamentos é a rotina rígida: No Albergue tem que acordar muito cedo. Nas ruas não, eu acordo a hora que eu quiser (D.C.A.). Novamente emerge o tema da liberdade, aqui vinculada ao exercício de escolha: é preciso, então, pensar no sentido da autonomia, enquanto objetivo das políticas voltadas para a população em situação de rua. 0 cerceio da autonomia fere a liberdade de pensar, de ser, de existir. Em uma instituição a autonomia pode ser ferida ou cerceada, tanto pelos mecanismos de controle institucionais quanto pela própria imposição da convivência forçada, como citado por vários dos entrevistados.

Para que um grupo populacional possa de fato ser inserido nas Políticas Públicas, deve-se primeiro entender como se organizam e se relacionam, quais são suas necessidades e vontades, histórias e memórias. Caso contrário, será uma inserção às avessas, pois quem deveria contribuir para a inserção estará na verdade impondo suas próprias concepções e valores, não dando crédito às experiências e demandas do outro. É preciso lembrar, entretanto, que o investimento em conhecer melhor o outro não deve servir como ferramenta para conseguir controlá-lo, pois controle não é inclusão, é opressão.

Segundo Castel (1994), o dispositivo da tutela recai tanto sobre o "pedinte" quanto sobre a classe trabalhadora como um todo. Mais do que mostrar que essa população é alvo de vigilância, ela é constituída pelos dispositivos de controle social. Deduz-se que, num certo sentido, as tentativas das entidades filantrópicas, grupos de direitos humanos e de prefeituras em conhecer o perfil populacional alimentam a disputa pela tutela sobre os moradores de rua.

Com relação aos serviços de segurança, os entrevistados dizem ser bastante marcante seu contato, sendo diária a relação que têm com os agentes da segurança privada e pública. Em seus relatos, esses agentes emergem como ícones da defesa do interesse dos demais munícipes, "não moradores de rua", deixando claro o quanto sua presença incomoda a sociedade. Lembrando Neves (1995),

[...] quanto mais pertences acumulam, quanto melhor se organizam para viver na rua, quanto mais demarcam simbolicamente, através de papelões e plásticos, um espaço para a privacidade ou menos vulnerável ao olhar do curioso, mais incitam a repressão, mais escandalizam os demais usuários do espaço público (Neves, 1995 p. 69).

Alguns referem uma relação tensa com os agentes da segurança pública, mencionando atos violentos e desrespeitosos: Às vezes acordo apanhando dos 
Guardas Municipais, eles jogam spray de pimenta; Eles não gostam que a gente durma na rua. Os PMs são mais educados. Chutam nosso pé e mandam a gente sair (D.C.L.).

Outros entrevistados lembram que a relação com os agentes da segurança pública tem regras e, se respeitadas, não há problemas. Entre as regras, a que os entrevistados mais citam é proibição de ir à zona de turismo, ou seja, entre a linha do trem e a praia: Em $1^{\circ}$ lugar Deus, mas a prefeitura é uma benção. Se não tiver depois da "linha da máquina", não tem problema, a guarda (guardas municipais) deixa a gente em paz numa boa (M.S.).

Tanto entre aqueles que se queixam da relação violenta quanto entre os que reconhecem a possibilidade de uma relação pacífica (desde que respeitadas as "regras"), em nenhum momento os agentes da segurança são vistos pelos entrevistados como atores responsáveis por sua segurança ou proteção. Ou seja, não se percebem como moradores da cidade, enquanto cidadãos a serem protegidos pelos agentes de segurança do município. Ao contrário, identificam esses agentes enquanto responsáveis por proteger os demais moradores da cidade de todos os riscos que a cidade possa oferecer, mesmo que esse "risco" seja caracterizado pela proximidade entre os moradores de rua e os "cidadãos de bem":

Às vezes parece até que a gente tem um problema que vai pegarnos outros [...] Eu queria saber por que que não pode ficar na rua. [...] Só sei que tem lugar que não pode e pronto. É só a gente chegar e o povo já pega o telefone, liga pra guarda [...] Eles chegam e tiram a gente de lá (C.D.).

A fala acima dá pistas do que fundamenta essa lógica distorcida que coloca a segurança pública em tarefa permanente de combater a população em situação de rua. Ao sugerir que o tratamento que recebem remete à relação que se estabelece em situações de "contágio", aponta para o cerne da questão: em uma sociedade capitalista, a miséria não é um produto, mas um resíduo inevitável, que se pretende manter afastado dos espaços sociais. 0 morador de rua é, então, o fantasma que assombra o resto da sociedade, denunciando a presença da miséria e, ao mesmo tempo, anunciando a possibilidade do futuro de qualquer um. Os moradores em situação de rua são "estranhos e prejudiciais ao espaço, sobretudo à sua imagem; os trajetos desses indivíduos causam desconforto e embaraço aos demais habitantes urbanos, onde o seu afastamento assume os traços de medo de contágio" (Martins, 200o, p. 04).

Isso ajuda a compreender por que, nas narrativas, o agente de segurança parece assegurar a proteção dos moradores da cidade, que não inclui proteger o morador em situação de rua: ele protege a todos, inclusive a si mesmo, do que o morador de rua representa.

\section{Atividades do cotidiano e plano para o futuro}

Algumas atividades cotidianas se caracterizam também como meio de estabelecer e sustentar relações com outras pessoas. Quando escolhem um lugar para dormir nas ruas, muitas vezes não dormem sozinhos, estabelecendo uma relação de convivência, de cuidado e de proteção mútua: $\varepsilon$ u durmo junto com outros carrinheiros (catadores de material reciclável que possuem carrinhos para coleta). Assim a gente se protege e protege também o carrinho (P.F.). Mesmo quem relata preferir dormir sozinho, conhece e estabelece contato com as pessoas que dormem próximas a ele.

Um dos entrevistados dorme em barracas montadas nas praias, para tomar conta das cadeiras, mesas, guarda-sóis, comidas e bebidas, para evitar ou diminuir a quantidade de furtos a esses lugares: Graças ao estacionamento e à barraca da praia, tenho sempre onde dormir, e ainda é um trampo (F.D.).

Os demais mencionam dormir em via pública. Os lugares onde costumam dormir são: perto de algum estabelecimento comercial com toldo, debaixo de marquises e nas proximidades do mercado municipal. Quando chove, o que é muito frequente na cidade de Santos, simplificam dizendo que é só procurar um lugar coberto: Se faz frio, o cobertor existe para isso, para esquentar. A gente dá um jeito. Tenho meu cobertor (S.P.).

Além das atividades envolvidas com o ato de dormir, também falaram de situações ligadas a outras necessidades básicas, como alimentação, higiene íntima, necessidades fisiológicas e sexo. Com relação ao banheiro, a maioria utiliza sanitários públicos como os da praia ou de algumas praças: $\mathcal{E}$ u vou no banheiro do cais, ou da praça Mauá (D.L.,); Uso ali, os banheiros da praia, mesmo (D.C.L.).

Outros preferem utilizar o banheiro de bares e 
padarias. Mas para que o dono ou responsável pelo estabelecimento permita o uso sem maiores questionamentos, há muitas vezes a presença de um vínculo previamente estabelecido. Em relação ao banho, os lugares citados foram os chuveiros das praias, o cais, o lugar onde vendem os materiais coletados durante o dia e entidades filantrópicas.

Com relação à alimentação, os relatos contrariam o mito existente na cidade de Santos de que, por ter uma população assistencialista, seria uma cidade na qual ninguém passa fome nas ruas. Por não conseguirem assegurar uma alimentação mínima diária, os entrevistados informam que precisam criar meios alternativos de enfretamento da fome: Tem que tapear, enganar a fome, quando ela aparece (S. P.).

Há pessoas que trabalham e usam o dinheiro para comprar comida, há pessoas que pedem dinheiro para poder se alimentar, há os que pedem comida em bares, padarias, restaurantes ou mesmo a transeuntes, e há quem recorra a instituições de caridade. Alguns procuram comida em lixos e há ainda quem beba água para "enganar" a fome. Já passei fome. Daí, fuçavalixo, pegava as frutas jogadas no mercadão (D.L.). Encontrar coisas no lixo ou contar com a doação significa viver com aquilo que é a sobra da sociedade.

Entre as necessidades básicas do ser humano, a prática sexual solicita especial atenção, pois é crime de atentado ao pudor quando feita em local público ou de grande visibilidade.

O desejo sexual se manifesta de formas diferentes. Em muitas situações, não se pode conter a vontade, ficando a encargo do exercício individual a possibilidade de reprimir apenas o ato. E como fazer para dar conta desses desejos nas ruas?

Existem diversas formas de lidar com essa situação nas ruas. Os entrevistados dizem que, entre as estratégias mais comuns para lidar com o desejo sexual, estão: reprimir e depois dar conta sozinho, arrumar alguém esporadicamente ou ter parceiros e parceiras fixas.

Para quem prefere ficar sozinho, há explicações variadas. Alguns moradores afirmam que preferem não manter relações sexuais por não poder confiar em ninguém: Mulher na rua não é bom ter não. Não dá pra confiar. Na rua é melhor ficar sozinho. Mas tem as gracinhas (travestis) por aí (M.S.). Alguns têm dificuldade em conseguir companheiras "adequadas" para o sexo: Mulher fácil de conseguir são aquelas noia, drogada, doidona. Eu não gosto. As mulheres da vida é difícil, porque não tenho dinheiro pra pagar(J.P.). Outros dizem evitar o sexo por opção: Essas mulher aqui do centro, Deus me livre. Não gosto não! Tenho medo de doenças. $\varepsilon$ como o medo faz acontecer coisas, então eu evito [...] Já sou separado da minha mulher há cinco anos e não tenho vergonha de dizer que até hoje amo ela (D.L.).

Quando aparece a vontade, a oportunidade e o/a parceiro/a, a tarefa de conseguir um local não se torna um obstáculo: Dá-se um jeito de fazer acontecer (D.C.A.). Os jeitos relatados foram: esperar até certo horário de pouca movimentação nas ruas; fazer cabanas de papelão; ir a um terreno baldio; alugar um quartinho barato no centro: Lá é baratinho. $R S$ 10,oo a hora (D.C.L.): Aí tem que ter a moeda (D.C.A.). Portanto, deixar de ter relações sexuais pode ocorrer por escolha própria ou por falta de dinheiro, mas não pela falta de lugar ou de parceiros/as.

Em suas narrativas houve grandes distinções em relação ao futuro. Alguns têm como plano de futuro viver e sobreviver nas ruas, outros pretendem sair dessa situação, arrumar um emprego, conseguir uma casa, se reunir novamente com a família: Não vai demorar muito tempo eu vou sair dessa situação (S.P.); Faço meus bicos, não desisto. Ainda não consegui assinar a carteira, mas vou conseguir! Vou alugar uma casa e poder dar um retorno para a minha família, ajudar elas! (D.L.).

Outros pretendem rever a família, mas sem necessariamente sair das ruas. Ainda há os que pretendem continuar com os trabalhos informais para não precisarem voltar a roubar para manter os vícios. Há planos que mudam, como no caso do D.C.A. que veio para a cidade em busca de sua família há cinco anos, e desistiu depois de todo esse tempo sem encontrar.

Cada novo fato adicionado às suas vidas, cada pessoa que entra ou sai de seu convívio, de sua rotina, altera o que haviam planejado para o futuro. Mas independentemente de quantas mudanças esses planos sofram, ou de quais são os planos, por mais simples que sejam, não ter planos parece ser o mesmo que não ter perspectiva de vida. 


\section{Considerações finais}

Morar nas ruas dá um novo sentido ao uso do espaço público. Os atos privados tornam-se públicos. O público, espaço coletivo de circulação, torna-se espaço de morar (Justo, 2005). Portanto, a presença do morador de rua provoca um impacto, porque torna público seu mundo privado e torna privado o espaço público. 0 caráter de transgressão dos moradores de rua emerge quando rompem com as regras de conveniência há muito estabelecidas pela sociedade contemporânea. A tirania da intimidade e o esvaziamento do espaço público (Sennett, 1988) são permeadas por fissuras estabelecidas cotidianamente pelos moradores em sua vida na rua. As formas de enfrentamento do preconceito e da "publicização" da privacidade são determinantes no processo de se fixar nas ruas.

Sobre a escuta, o registro e a análise das narrativas de memórias e planos de vida de pessoas em situação de rua, é importante destacar que se caracterizam por um processo cheio de desafios. Não é fácil ouvir sobre vidas sofridas, sobre tristezas, angústias. Não é fácil ver situações que parecem caóticas, da perspectiva dominante - a mesma que inclui os universos do pesquisador, dos gestores e de muitas das pessoas que transitam pelos espaços públicos urbanos. No método de escuta de narrativas de memórias de vida, há a constante possibilidade do sofrimento do ouvinte, ao estar com pessoas que passam por necessidades e que não gostariam de viver onde vivem e como vivem. Por este motivo, é igualmente difícil ouvir e legitimar as falas de algumas destas pessoas ao afirmarem que gostam de estar onde estão, que se acostumaram a viver desta forma e que não trocariam por nada o lugar e as condições em que vivem. Se ouvir o sofrimento alheio incomoda e produz sofrimento para o ouvinte, há também um desconforto, desta vez pelo estranhamento, em escutar narrativas de pessoas que, diferente de tantas outras que vivem nas ruas, trazem em suas memórias e planos a afirmação da permanência. Da mesma forma, para muitos que hoje habitam as ruas, é insustentável o discurso de que morar em uma casa seja melhor.

Acredita-se que seja possível produzir encontros significantes, através de construção e valorização de memória e de planos de vida. É preciso, para tanto, um olhar mais ampliado e menos etnocentrista, para que as ações possam ganhar formas mais criativas e efetivas.

\section{Contribuição dos autores}

Padilha redigiu o projeto de pesquisa, realizou a pesquisa de campo e a redação do texto em todas as suas fases. Costa orientou a pesquisa, realizou parte da pesquisa de campo e contribuiu com a redação do texto em todas as suas fases. Marquetti contribuiu com a redação do texto em todas as suas fases.

\section{Referências}

BARROS, D. D.; LOPES, R. E.; GALHEIGO, S. M. Projeto Metuia: terapia ocupacional no campo social. O Mundo da Saúde, São Paulo, v. 26, n. 3, p. 365-369, 2002.

BRASIL. Ministério do Desenvolvimento Social. Norma Operacional Básica NOB/SUAS. Brasília, DF, 2005 .

BRASIL. Ministério do Desenvolvimento Social. Tipificação nacional de serviços socioassistenciais. Brasília, DF, 2009.

CASTEL, R. Da indigência à exclusão, à desfiliação: precariedade do trabalho e vulnerabilidade relacional. In: LANCETTI, A. (Org.). SaúdeLoucura 4. São Paulo: Hucitec, 1994. p. 21-48.

CERTEAU, M. A invenção do cotidiano 2: morar, cozinhar. Petrópolis: Vozes, 1996.

COSTA, S. L. Os sentidos da comunidade: construções intergeracionais de memória coletiva na Ilha das Caieiras, em Vitória, ES. 20o8. Tese (Doutorado em Psicossociologia de Comunidades e Ecologia Social) - Universidade Federal do Rio de Janeiro, Rio de Janeiro, 2008.

COSTA, S. L. Terapia ocupacional social: dilemas e possibilidades da atuação junto a povos e comunidades tradicionais. Cadernos de Terapia Ocupacional da UFSCar, São Carlos, v. 20, n. 1, p. 43-54, 2012. 
COSTA, S. L.; CARVALHO, E. N. As potências da narrativa. In: LOPES, K. J. M.; CARVALHO, E. N.; MATOS, K. S. A. L. (Org.). Ética e as reverberações do fazer. Fortaleza: UFC, 2011. p. 60-73. (Coleção Diálogos Intempestivos).

GASPAR, E. W. O cotidiano da rua: um estudo através da percepção do gazeteiro de Fortaleza. Fortaleza: Fundação Edson Queiroz: Universidade de Fortaleza, 2006.

GEERTZ, C. A interpretação das culturas. Rio de Janeiro: Guanabara-Koogan, 1989.

GHIRARDI, M. I. G. et al. Vida na rua e cooperativismo: transitando pela produção de valores. Interface: Comunicação, Saúde, Educação, Botucatu, v. 9, n. 18, p. 601-610, 2005.

GOURHAN, A. L. A. O gesto e a palavra: memória e ritmos. Lisboa: Perspectivas do Homem, 1966. v. II.

HALBWACHS, M. A. Memória coletiva. São Paulo: Centauro, 2006.

HELLER, A. O quotidiano e a história. Rio de Janeiro: Paz e Terra, 1972.

JUSTO, M. G. "Exculhidos": ex-moradores de rua como camponeses num assentamento do MST. 2005. Tese (Doutorado em Geografia) - Faculdade de Filosofia, Letras e Ciências Humanas da Universidade de São Paulo, São Paulo, 2005.

JUSTO, M. G. Vida nas ruas de São Paulo e alternativas possíveis um enfoque sócioambiental. InterfacEHS, São Paulo, v. 3, n. 1, p. $1-27,2008$.
LAROUSSE CULTURAL. Dicionário Larousse Cultura da Língua Portuguesa. São Paulo: Nova Cultural, 1999.

LIRA, G.; CATRIB, A. M. F.; NATIONS, M. K. A narrativa na pesquisa social em saúde: perspectiva e método. RBPS, Vitória, v. 16, n. 1/2, p. 59-66, 2003.

MAGNI, C. T. Nomadismo urbano: uma etnografia sobre moradores de rua em Porto Alegre. Porto Alegre: Edunisc, 2006.

MARQUETTI, F. C. A ação como precursora do pensamento no humano. Cadernos de Terapia Ocupacional da UFSCar, São Carlos, v. 19, n. 2, p. 215-228, 2011.

MARTINS, J. S. A sociabilidade do homem simples. São Paulo: Hucitec, 2000.

MAYOL, P.; GIARD, L.; CERTEAU, M. A invenção do cotidiano. Petrópolis: Vozes, 1996.

NEVES, D. P. Comentário dos assessores sobre o perfil da população de rua. In: ROSA, C. M. M. (Org.). População de rua: Brasil e Canadá. São Paulo: Hucitec, 1995. p. 131-134.

PÁDUA, E. M. M.; MAGALHÃES, L. V. Terapia ocupacional: teoria e prática. São Paulo: Papirus, 2003.

SENNETT, R. O declínio do homem público: as tiranias da intimidade. 4. ed. São Paulo: Companhia das Letras, 1988. 